\title{
REPRESENTACIÓN DE LA MINORÍA ENTRE LA MINORIA: RELACIONES INTER-GÉNERO E INTER-ÉTNICAS EN LA PUBLICIDAD
}

\author{
PATRICIA IZQUIERDO IRANZO \\ Universidad Rey Juan Carlos (Madrid)
}

\section{INTRODUCCIÓN}

Entre las lacras sociales más perjudiciales se encuentran el sexismo y el racismo. Se dice que son acciones de discriminación contra minorías, pero los grupos que la padecen están en minoría únicamente respecto a su pleno acceso a variados derechos. Si cada uno por separado resulta tan dañino, nos preguntamos acerca de la intersección entre ambos. Entendemos que cada conjunto poblacional aludido (mujeres, inmigrantes) es complejo en sí mismo y posee una miscelánea de elementos contextuales y psicosociales propios, pero además, el nuevo conjunto resultante de la intersección tiene también características exclusivas que no consisten en la simple suma de las anteriores sino en una fusión privativa, es decir, no es "lo étnico + lo femenino", sino "lo étnico-femenino». Nuestra propuesta de crear una única categoría de análisis, lo étnico-femenino, parece adecuada para estudiar características y estatus sociales que convergen en la unicidad de los sujetos. De hecho esta cuestión ha sido tratada desde la psicología, y los resultados son evidentes: cuando hay variedad de roles o identidades es menos conflictivo para la propia persona que no haya interferencias entre dichos roles, y por lo mismo, cuanta mayor fusión haya, mayor identificación con uno mismo existirá: "Those women who cognitively separate their identities may be more likely to locate one identity (e.g., woman) as the source of difficulties in their other identity (e.g., black person)»1.

En el imaginario colectivo la categoría de inmigración funciona como sinónimo de la idea de raza, además esa noción de raza se refiere sólo a aquellos grupos cuyos rasgos salientes permiten al autóctono ubicarlos en un lugar de

1. SETTLES, Isis H.: «Use of an Intersectional Framework to Understand Black Women's Racial and Gender Identities», Sex Roles, 54:9/10 (2006), p. 597. 
origen considerado como más pobre y/o inferior. Por ello creemos que a los problemas de xenofobia es más adecuado llamarlos racismo, puesto que el rechazo no es tanto a lo extranjero en general sino a ciertos orígenes externamente identificables. Por ello las unidades de análisis que han sido seleccionadas son aquellas mujeres cuya apariencia nos permite fácilmente ubicarlas en aquellos grupos que tradicionalmente mayor racismo han sufrido ${ }^{2}$. Para ello recurrimos a un indicador, los rasgos salientes definidos bien a través de las características fisonómicas, bien a través de los aditamentos ${ }^{3}$.

Para concretar un espacio en el que estudiar la categoría descrita, seleccionamos la publicidad, entendiendo que su condición de producto mediático omnipresente de ficción se nos ofrece como una superficie simbólica suficientemente expresiva y cotidiana para observar la cuestión de las identidades étnicas y culturales. Siendo el tema de interés para este estudio transversal a toda la sociedad, nos parece adecuada la selección de la publicidad como objeto material de análisis porque también es transversal a los grupos mediáticos. Es decir, mientras que un anuncio va a preservar su relato intacto independientemente de la cadena o cabecera en la que sea difundido, por este mismo motivo una noticia sí puede ver modificado su enfoque y análisis. La elección de un producto mediático que define su plan de medios (dónde y cuando se emite) con independencia de las tendencias de los soportes ${ }^{4}$, pretende, precisamente, eliminar el sesgo ideológico en una cuestión que por su propia naturaleza se presta a ello5.

Acorde a las inquietudes planteadas, definimos una serie de objetivos, el primero, de carácter más genérico, pretende ayudar a contextualizar el grueso de la cuestión: explorar y describir cómo se representa a la mujer étnica y racialmente diferente a la autóctona en la publicidad. En un nivel más concreto nos propusimos otros objetivos más específicos, por un lado, observar si en los estereotipos raciales femeninos publicitarios se refleja la consideración de la inmigración como problema que existe entre la población española, y por otro, reflexionar acerca de las conexiones entre representaciones e integración.

Especialmente interesa y preocupa la afirmación recogida en el primero de los objetivos específicos, que no responde a opiniones subjetivas o alarmistas

2. Esta decisión responde a una circunstancia concreta del contexto migratorio español, los grupos de inmigrantes procedentes del este de Europa son muy numerosos, y aunque también padecen la xenofobia debido a su status inmigrante, su origen étnico caucásico, potencialmente les excluye de padecer el racismo de corte más biológico.

3. Este indicador puede producir desajustes con la realidad, habrá mujeres consideradas como unidades de análisis que sí pertenezcan a la población nativa (y viceversa), sin embargo su elección como muestra sigue siendo válida porque, por ejemplo, si en un anuncio aparece una mujer con rasgos orientales, aunque fuese española ejerce de mujer oriental.

4. Término técnico publicitario que designa al medio de comunicación cuando éste se convierte en soporte de difusión de alguna pieza publicitaria.

5. A pesar de la existencia de prácticas comunes a todos los medios cuando se analiza la cobertura informativa de la inmigración, está constatado que dicho tratamiento está directamente relacionado con el grupo empresarial (e ideología) al que pertenezca la información analizada. 
sino que da cuenta de ello uno de los más relevantes instrumentos de medición de la temperatura social como es el barómetro del CIS, el cual registró a lo largo de todo 2007 la inmigración entre el tercer y cuarto puesto de la lista de problemas percibidos ${ }^{6}$.

En los abundantes estudios que recientemente proliferan en torno a la cuestión migratoria detectamos algunas lagunas sistemáticas. Una es la observación de la cuestión migratoria olvidando la perspectiva de género ${ }^{7}$, y otra que cuando se aborda el reflejo de la inmigración en los medios de comunicación el foco de estudio se cierra a lo más puramente informativo y en especial sobre los ya considerados medios "tradicionales»". Entendemos que la relevancia del presente estudio viene dada al intentar cubrir en parte las brechas detectadas, centrando el estudio de la inmigración en un aspecto muy concreto y novedoso: la mujer y la publicidad de manera conjunta.

En principio cabe esperar que al tratarse de un colectivo doblemente marginado y con poca voz en su propia representación, la mujer étnica sufra una severa estereotipación, hecho que indudablemente dificulta la normalización de su presencia en nuestra sociedad. Pero también intuimos que dicho tratamiento se verá matizado dada la idiosincrasia publicitaria. Esto es, el tipo de representación esperada transita en un terreno incómodo y tal condición es contraria a la práctica publicitaria. Por ello prevemos que la publicidad encontrará alguna manera de traducir el retrato socialmente negativo de grupos discriminados en representaciones útiles al siempre laudatorio discurso publicitario?.

6. El Centro de Investigaciones Sociológicas (CIS) realiza mensualmente macroencuestas para recoger la opinión de la población, entre otros recoge los problemas percibidos (http://www.cis.es/cis/ opencms/ES/2_barometros/). A lo largo de todo el 2007, en el listado de problemas percibidos se mantuvieron a la cabeza paro y ETA alternándose entre el $1^{\circ}$ y $2^{\circ}$ puesto, y vivienda e inmigración se alternaron sistemáticamente la $3^{\mathrm{a}}$ y $4^{\mathrm{a}}$ posición. Además la puntuación de estos cuatro temas se cuantifica con pequeñas diferencias entre sí (salvo cuando la preocupación por ETA en algún mes puntual se dispara presumiblemente por alguna acción violenta de la banda), y a gran distancia del resto de problemas registrados a partir de la $5^{a}$ posición.

7. Una significativa y valiosa excepción al respecto viene recogida en: TRINIDAD, Antonio; CARRERO, Virginia y SORIANO, Rosa Ma: Teoría fundamentada "Grounded Theory". La construcción de la teoría a través del análisis interpretacional, Madrid, CIS, 2006. En p. 127 y ss. se detalla una aplicación práctica de la mencionada teoría a una rigurosa investigación cuyo objeto de estudio es la inserción por parte de las mujeres marroquíes inmigrantes.

8. Significativa excepción al estudio de la representación de la inmigración fuera del ámbito informativo es: LACALLE ZALDUENDO, Charo: «Inmigración y marginalidad. La representación televisiva del "otro» en las series españolas de ficción", Trípodos, n extra (2003), pp. 533-544 y salvedad llamativa del abordaje del racismo fuera de los medios tradicionales es el libro: LEUNG, Linda: Etnicidad virtual. Raza, resistencia y world web web, Barcelona, Gedisa, 2007.

9. Con esta hipótesis no se pretende acusar ni incriminar la práctica publicitaria ni a sus profesionales. De alguna manera todos somos publicitarios, o dicho de otra manera, probablemente si de un día para otro reemplazásemos a todos los profesionales de la publicidad por sujetos de la misma sociedad, los anuncios seguirían utilizando los mismos estereotipos y haciendo semejantes juegos metafóricos. Con ello expresamos la creencia de que los mecanismos de reproducción y representación subyacen transversalmente a las sociedades y por tanto a muchas profesiones, pero pocas producen piezas tan públicas y fácilmente sometibles a juicio como la publicidad. 


\section{IDENTIDADES Y PRESENCIAS}

Un elemento esencial para la definición de las identidades son los lugares. En ellos se puede tener una presencia física, la sociedad donde cada cual habita, o se puede tener una presencia simbólica, a través de la representación pública y social que exista sobre el grupo con el que cada uno se siente identificado. Encontrar la posición cómoda de nuestra identidad entre el lugar habitado y el representado es cada vez más una cuestión individual y con consecuencias directas en la autoestima (salud psicológica) y el bienestar personal. Una cuestión clave es que las identidades simbólicas de quienes interesan en este estudio -inmigrantes y mujeres-, han sido y son tradicionalmente forjadas por grupos de poder entre los que no se encuentran los propios representados. Además en el caso del grupo inmigrante, la injerencia externa no sólo abarca el lugar representado (identidad simbólica) sino también el lugar habitado (identidad social) en la medida en que, en los lugares a los que se desplaza a vivir, carece de plenos derechos de ciudadanía, ocupa un estatus social inferior y padece el temor de sus vecinos autóctonos que identifican la inmigración con amenaza y competencia por los recursos sociales.

\subsection{Lugares sociales}

Hoy día, y cada vez más, los conceptos de cultura y sociedad no son sinónimos, como tampoco lo es el de rasgos étnicos respecto a los anteriores. En algún momento de la historia de la humanidad estas tres nociones estuvieron mucho más interrelacionadas, sin embargo el grado de analogía entre las tres ha ido variando por una serie de motivos, los mismos que explican las grandes transiciones demográficas mundiales (pandemias, guerras, pobreza, opresión...) ${ }^{10}$. La búsqueda de mejores condiciones de vida es el motor de los movimientos poblacionales, lo fue de los millones de españoles que durante siglos y hasta los años setenta estuvieron saliendo fuera de nuestras fronteras, y lo es ahora de otros tantos millones que llegan a España procedentes de diversos rincones del planeta.

\subsection{Lugares mediáticos}

Dotar de contenido a las identidades es una tarea compleja, en parte puede responder a estrategias políticas y culturales e intereses económicos, pero también es necesario sumarle una buena dosis de la espontaneidad y el acontecer social. Por ello no resulta fácil señalar con precisión el origen de cada uno de los significados que teje el conjunto de rasgos que compone cada identidad, como también es complicado distinguir cómo deriva el usufructo identitario que cada persona realiza respecto a su grupo de pertenencia (cómo la identidad grupal afecta al sujeto) o el uso valorativo que otros grupos realizan desde su visión ajena al mismo (cómo la identidad grupal afecta a la percepción del grupo por

10. Del CAmpo, Salustiano: "Cuatro transiciones demográficas», Sistema. Revista de Ciencias Sociales, 201 (2007), pp. 3-11. 
parte de otros grupos). Sin embargo sí es fácil valorar que hoy día los medios de comunicación, como actores sociales que son, juegan un papel determinante en todos estos procesos. La cuestión de la influencia y el débito de la actividad mediática en las identidades debe abordarse desde el estudio de las representaciones, por ello, y acorde con los objetivos planteados, nos proponemos averiguar el retrato que el discurso publicitario difunde de aquellos grupos de identidad étnica diversa a la población autóctona, y en concreto el de la mujer.

El repaso documental de rigor nos lleva fuera de nuestras fronteras. Afortunadamente el interés por la representación mediática de la diversidad crece como campo de estudio en España, sin embargo, como ya se ha señalado en la introducción, de manera generalizada, y esperemos que sólo por el momento, se circunscribe al ámbito informativo ${ }^{11}$. Si además se introduce la variable de género, la ausencia de referencias es mucho más evidente ${ }^{12}$. A diferencia de la realidad española, la investigación anglosajona sí tiene una larga tradición en el estudio de la diversidad étnica en la publicidad ${ }^{13}$, de hecho el estereotipo étnico está muy estudiado desde la psicología, la sociología y la antropología: actitudes, interrelaciones, autoestima... y de esta forma los estudios sobre medios obtienen de los avances en otros campos sólidos referentes que aplicar a la especificad de su materia.

\subsubsection{Persistencias representativas}

La referencia pionera es la de Shuey, King y Griffith ${ }^{14}$ que realizaron el primer análisis de contenido acerca del sesgo étnico en anuncios de revistas norteamericanas de 1949 a 1950. Los resultados fueron contundentes: los autores constataron una absoluta infra-representación de la población afroamericana

11. Entre las escasas referencias encontradas sobre el estudio de la diversidad fuera del ámbito informativo y específicamente centrado en la publicidad destaca: VV.AA: Diversidad y Publicidad. Observatorio 2004, San Sebastián, MUGAK y XENOMEDIA, 2004 y BALADRÓN PAZOS, Antonio et alt.: La Publicidad se acerca a la inmigración. Un factor de integración de la diversidad cultural, Observatorio de las Realidades Sociales y de la Comunicación, Madrid, 2007.

12. En algunas investigaciones la categoría género forma parte del conjunto de variables de estudio respecto a la representación de la inmigración pero sin que sea el interés central. Entre los estudios que específicamente sí orbitan alrededor de lo femenino encontramos: BERNÁRDEZ RODAL, Asunción (Dir.): Mujeres inmigrantes en España. Representaciones en la información y percepción social, Madrid, Fragua, 2007. Sin embargo, de nuevo vemos que el interés se centra únicamente en el género informativo.

13. La reacción explicativa inmediata ante esta situación es pensar que la diversidad poblacional en los países anglosajones es mucho más antigua que en la sociedad española; sin embargo en países como Canadá la inmigración -de origen no europeo- data también de la década de los noventa. Así mismo cabe pensar que la abundancia de estudios al respecto se deba a que en estos países la mezcla racial de población es muy amplia, en este sentido quizá sorprenda saber que según las estadísticas gubernamentales en EE.UU sólo el 12,6\% de la población es afroamericana.

14. Shuey, A.M.; King N. and Griffith, B.: «Stereotyping of Negroes and Whites: An analysis of magazine pictures», Public Opinion Quarterly, 17 (1953), pp. 281-287. Citado por Plous, S. and NEPTUNE, D.: «Racial and gender biases in magazine advertisement», Psychology of Women Quarterly, 21 (1997), p. 629. 
registrando su presencia en tan sólo un $0,6 \%$ de los anuncios. Además en las escasas ocasiones de aparición, el 95,3\% eran presentados como trabajadores no cualificados y el resto como atletas o gente del espectáculo. Observamos que el porcentaje de presencia se relaciona con la época del estudio, así Kassarjian ${ }^{15}$, cuyos datos abarcan fechas similares a las de Shuey et alt. (1946-1965), también proporciona cifras paupérrimas de representación: «Blacks models less than 1/3 of $1 \% »$. Pero efectivamente según avanza el tiempo estas referencias se ven exponencialmente superadas: "The percentage of advertisements with African Americans increased significantly over time, growing from $8.3 \%$ in the $1980 \mathrm{~s}$ to $11.8 \%$ in the $1990 \mathrm{~s} »^{16}$.

Aún así muchos estudiosos hoy en día coinciden en señalar que pese a la mejora de las últimas décadas, nunca se alcanza la total paridad demográfica ${ }^{17}$. De la infra-representación de las minorías étnicas en la publicidad española también hay constancia: «Pese a que la tasa de crecimiento interanual de inmigrantes viene duplicándose desde los últimos seis años, la publicidad ha mantenido la representación de la variedad racial estable alrededor de un $3 \%{ }^{18}$.

Respecto a la presencia de la diversidad es importante señalar que, si bien se ha constatado fehacientemente la infra-representación de la población negra, es aún más destacable en el resto de grupos étnicos no-blancos, pues son directamente inexistentes ${ }^{19}$. Su ausencia es también una constante en la investigación, pocas veces se estudian expresamente, y aún más llamativas resultan las justificaciones encontradas ante tal silencio, bien porque las escasas ocasiones en las que se han estudiado otros grupos étnicos los resultados han sido parecidos a los hallados al estudiar la población afroamericana, bien por "the difficulty of classifying Light-skinned models by race ${ }^{20}$. Entre las escasas referencias que sí prestan atención a grupos no-blancos y no-negros, destaca la de Beasley DeLouth et alt. ${ }^{21}$, que nos ofrecen datos muy concretos: población asiática: $9,1 \%$, presencia en imágenes mediáticas: inferior a $1 \%$; población latina: $25,8 \%$, presencia en imágenes mediáticas: inferior a $5 \%$. Por el contrario, en su estudio, los hombres negros registran una sobre-representación desmesurada, eso sí,

15. KASSARIIAN, H. H.: «The Negro and the American advertising, 1946-1965», Journal of Marketing Research, 6 (1969), pp. 29-39. Citado por Millard, Jennifer E. and GRANT, Peter R.: "The Stereotypes of Black and White Women in Fashion Magazine Photographs: The Pose of the Model and the Impression She Creates», Sex Roles, 54 (2006), p. 661.

16. Plous, S. and NePtune, D.: Op. cit., p. 633.

17. Ibíd., pp. 630 y 638, citan una serie de estudios de diversos autores que avalan dicha afirmación.

18. IzQUierdo IRANZO, P.: Representaciones étnicas en la publicidad gráfica española. Análisis de El País Semanal 1997-2003, Madrid, Servicio de Publicaciones de la Universidad Complutense, Colección Tesis Doctorales digitales, 2004. p. 235.

19. Millard, Jennifer E. and Grant, Peter R.: Op. cit., p. 670.

20. Plous, S. and NePtune, D.: Op. cit., p. 641.

21. Beasley Delouth, Tara-Nicholle; PIRSON, Brigitte; HitchCock, Daryl and RIENZI, Beth: «Gender and Ethnic Role Portrayals; Photographic Images in Three Californian Newspapers", Psychological Reports, 76:2 (1995), p. 494. 
Representación de la minoría entre la minoría: relaciones inter-género e inter-étnicas en...

sólo en la sección de deportes, población negra masculina: 7\%, presencia en imágenes mediáticas de la sección de deportes: $71 \%$.

Los avances también se han observado en otra de las cuestiones claves del estudio de las representaciones como son los roles desempeñados. En el terreno concreto de la publicidad las personas de etnia negra empiezan a ser asociadas a productos como los coches o los desodorantes, con los que antes no se les relacionaba en los anuncios; también se registra como positivo la disminución del estereotipo de servants y del de unskilled labourers, pero sin embargo han aumentado los de athlets, entertainers y recipients of charity ${ }^{22}$. Esta realidad no debe extrañar puesto que a su vez coincide con el estereotipo del negro que circula en las calles ${ }^{23}$ : "Black people have been and continue to be characterized in terms of long-standing derogatory stereotypes concerning their limited intelligence and work ethic, as well as their aggressiveness» ${ }^{24}$.

En definitiva parece que una vez superada una primera fase de representación mediática alarmantemente discriminatoria y segregacionista de grupos étnicos diversos al dominante ${ }^{25}$, se produce un estancamiento que llega hasta nuestros días.

La obstinación es característica común entre la representación publicitaria de lo étnico y la de lo femenino. Ya en 1971 Courtney y Lockeretz ${ }^{26}$ señalaron cuatro estereotipos clásicos sobre la representación de género: la mujer permanece en casa, la mujer no toma decisiones ni hace cosas importantes, la mujer es dependiente del hombre y para el hombre la mujer es sobre todo un objeto sexual. La investigación ha demostrado el sistemático abuso de estos estereotipos por parte de la publicidad; únicamente parece haber mejorado el primero de ellos debido a la incorporación masiva de la mujer al mundo laboral extra hogareño, sin embargo este progreso parece haberse producido a costa del empeoramiento del último de los estereotipos: "At the same time, increases in work-role equality seem to have been offset by a concomitant trend toward displaying women as decorative and sexualized $»^{27}$.

Y hablando de evidencia científica, no podemos olvidar las categorías clásicas expuestas por Goffman (licensed withdrawal, function ranking, relative size, ritualization of subordination, femenine touch and family ${ }^{28}$ acerca de la presencia publicitaria de la mujer y los abundantes estudios que desde entonces

22. Plous, S. and NePtUne, D.: Op. cit., p. 630.

23. Una extensa lista de referencias relevantes sobre el well documented negative stereotype of Black people in the United Status and Canada, podemos en contrarla en MILLARD, Jennifer E. and GRANT, Peter R.: Op. cit., p. 665.

24. Ibíd., p. 661.

25. A tenor de las fechas en las que hemos referido los datos más abrumadoramente negativos y las fechas en las que se empiezan a constar mejoras al respecto, deducimos que éstas se relacionan con el movimiento de los Derechos Humanos.

26. Courtney, A.E. and LockeretZ, S. W.: "A woman's place: An analysis of the roles portrayed by women in magazine advertisements", Journal of Marketing Research, 8 (1971), p. 92.

27. Plous, S. and NePTUNe, D.: Op. cit., p. 628.

28. GoffMAN, Erving: Gender advertisements, London, The Macmillan Press, 1979. 
vienen ratificándolas: "Women in magazine advertisements are still portrayed stereotypically and that the prevalence of most of these stereotypes has not declined significantly since Erving Goffman ${ }^{29}$.

La persistencia principal tiene que ver con el papel secundario de la mujer, pero además, como comentábamos, su consideración como objeto sexual ha ido aumentando, su cuerpo aparece expuesto intensa y frecuentemente y desde luego con mucha mayor asiduidad que el de los hombres. Es cierto que el mayor número de modelos desnudas o semidesnudas no permite por sí solo hablar de un empeoramiento en la representación de la mujer ya que la concepción del cuerpo también ha cambiado en la sociedad, pero el hecho de que los mismos estereotipos lleven décadas repitiéndose sí permite hablar de una persistente influencia negativa en la cuestión de la percepción y la autopercepción de la mujer.

\section{ANÁLISIS DE LA PRESENCIA DE LA MUJER ÉTNICA EN LA PUBLICIDAD}

Anteriormente se ha comentado que la cuestión étnica en la publicidad hace tiempo que se estudia en el mundo anglosajón, sin embargo estos estudios tenían lagunas significativas, algunas de ellas derivadas de la ausencia de incluir género como variable protagonista junto a $\mathrm{raza}^{30}$. Por ello las primeras referencias sobre el estudio de la mujer no-blanca en la publicidad se hacen esperar aún unas décadas respecto a los primeros estudios étnicos en la publicidad anteriormente comentados y que datan de los años 50. Este «retraso» en el estudio evidencia de entrada un menor interés por la cuestión específica de género y, una vez más, nos permite denunciar las persistencias representativas previamente ilustradas tanto en la cuestión étnica como en la de género.

Para enriquecer el análisis y poder establecer comparaciones entre el ámbito nacional e internacional, se ha realizado una investigación ad hoc. El corpus de análisis está integrado por la totalidad de anuncios publicados en EL PAÍS SEMANAL entre 1997 y 2006, que contuvieran alguna figura femenina adulta con rasgos no autóctonos, y para cuya selección se han tenido en cuenta los indicadores y definiciones detalladas en la introducción. La primera cuestión destacable es que sólo encontramos 86 anuncios diferentes ${ }^{31}$ que contengan

29. Millard, Jennifer E. and GRANT, Peter R.: Op. cit., p. 669.

30. Coltrane, Scott and Messineo, Melinda: «The Perpetuation of Subtle Prejudice: Race and Gender Imagery in 1990s Television Advertising», Sex Roles, 42:5/6 (2000), p. 364.

31. 86 es el número total de anuncios que sin repeticiones ofrecen al menos una figura femenina de rasgos no autóctonos. Obviamente el número de apariciones de mujeres no autóctonas es superior a 86 debido a la repetición de las inserciones publicitarias. Para la conformación del corpus sólo se ha seleccionado una única aparición de cada anuncio, es decir que los 86 anuncios analizados son diferentes entre sí. Entendimos que incluir en el corpus las inserciones que repiten campañas ya publicadas únicamente permitiría establecer el porcentaje de presencia con exactitud respecto al total del volumen publicitario editado, pero consideramos que esta exactitud puramente cuantitativa no es muy relevante debido a que la certeza de que la mujer de rasgos no autóctonos está profundamente infra-representada está suficientemente demostrada al apa- 
las unidades de análisis deseadas, y la mayoría de ellos sólo contienen una figura femenina ya que en 86 anuncios encontramos 96 mujeres de rasgos no autóctonos. Tratándose de una publicación semanal, habiendo estudiado un intervalo temporal de casi una década y tratándose de una de las publicaciones con mayor liderazgo de lectores consolidado ${ }^{32}$, la cifra de 96 mujeres arroja una notoria infra-representación en la publicidad española de mujeres cuyos rasgos nos permiten relacionarlas con las nuevas poblaciones.

Entre las referencias más interesantes acerca de la representación publicitaria de la mujer negra en Estados Unidos destacan los estereotipos identificados por Collins $^{33}$ : Jezebel es hipersexy y promiscua, representa el deseo; Mammy está totalmente dedicada a la crianza y Saphire es maleducada y grosera. Esta clasificación se ha consolidado al punto de haber tenido un uso terapéutico y servir como referente en diversos ámbitos ${ }^{34}$. En el análisis de la mujer étnica en la publicidad gráfica española, se identifica el primero de los estereotipos pero ni el segundo ni el tercero, cuestión esperable ya que entendemos que estos usos de la mujer negra por parte de la publicidad estadounidense, Mammy y Saphire, están muy unidos a su contexto histórico y de alguna manera derivan de la iconografía de la época de la esclavitud, al igual que ocurre con los estereotipos de Aunt Jemima y Sambo, y cuya extinción en el mundo de las representaciones mediáticas se cita como un importante avance al respecto ${ }^{35}$.

\subsection{Jezebel en la publicidad española}

Como decíamos, en nuestro análisis sí que se ha identificado con claridad el estereotipo de Jezebel, la mujer étnica hipersexy y promiscua. Además este uso como objeto sexual abarca distintos grados. En el lado más extremo encontramos una mujer que siempre es mulata o negra, depredadora de un indiferente hombre blanco (imagen 1). Esa aparente indiferencia pretende apuntar la dirección de la culpabilidad, como también la señala el eslogan: «el oscuro objeto de deseo", al lado de un rostro en primer plano de una mujer latina mirando desafiantemente, con los labios entreabiertos, el pelo cayéndole por el rostro y sobre un fondo de playa desierta en tonos muy cálidos (imagen 2); en

recer únicamente en 86 campañas diversas. Sin embargo incluir las repeticiones de los anuncios en el corpus de análisis sí podría producir un sesgo en cuanto a la mayor presencia de ciertos estereotipos o rasgos: en el momento en que una sola campaña tuviera un mínimo de presión estacional o intensificación en las apariciones, precisamente dada la escasa cantidad de anuncios con mujeres no autóctonas, se producirían serias alteraciones.

32. EL PAÍS SEMANAL durante la década estudiada ha permanecido a la cabeza del ranking de número de lectores de suplementos alternando su posición entre los tres primeros puestos según el AIMC (Asociación para la Investigación de Medios de Comunicación), en http://www. aimc.es/.

33. Collins, P.H.: "The sexual politics of black womanhood» in P.B. BART and E.G. MORAN (eds.): Violence against women: The bloody footprints California, Sage, 1993, pp. 85-104, citado por SETTLES, Isis H.: Op. cit., p. 590.

34. WEST, C.M.: "Mammy, Jezebel, and Sapphire: Historical images of black women and their implications in psychotherapy", Psychotherapy, 32 (1995), pp. 458-466.

35. Plous, S. and NePTUNE, D.: Op. cit., p. 630. 


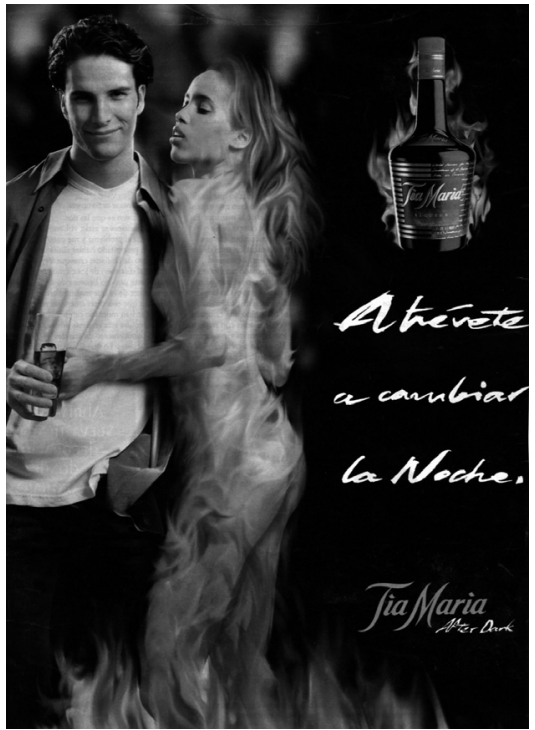

Imagen 1.

el primero de los ejemplos mencionados la culpabilidad viene además indicada porque la mujer en cuestión está rodeada de llamas, como si emergiera del mismísimo infierno. Las escenas en las que una mujer negra o mulata devora a un hombre blanco son las únicas ocasiones en las que se relaciona a mujeres no blancas con hombres blancos, en el resto de situaciones de pareja, éstas nunca son mixtas en cuanto al grupo étnico. El hecho de que para el grado de depredación más exagerado de la mujer hacia el hombre se use a la mujer negra no extraña, hay evidencia

científica que demuestra que el hombre la considera una mujer "más salvaje», y esa idea a la vez se relaciona con mujeres más activas sexualmente ${ }^{36}$.

Afortunadamente los casos comentados son los más extremos y menos frecuentes, el uso «corporal» de la mujer étnica también incluye situaciones menos degradantes en el sentido de que ellos siguen siendo menos activos y protagonistas (= menos culpables), pero al menos ya aparecen en escena. En estos casos de culpa compartida las parejas ya sí pertene-

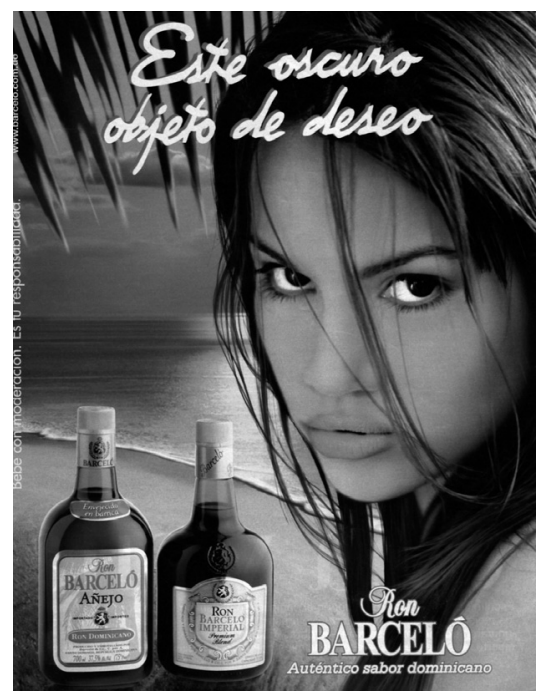

Imagen 2 .

36. Ibíd., p. 637 y ss. Estos autores exploran la imagen de la mujer negra como animal depredador en la publicidad partiendo de ciertas imágenes pornográficas recurrentes al respecto y del propio slang anglomericano que apela habitualmente a metáforas animales para referirse a la mujer negra. Para ello centran su análisis en las caracterizaciones: posturas y aditamentos, especialmente se centran en la vestimenta animal print. Sus hipótesis están basadas en los estudios previos (Ibíd., pp. 639 y 640): «Participants also believed that women who wore animal prints were more sexually active than other women, less educated, lower income (...)». Plous y Neptune concluyen que "the individuals in their study viewed animal-print wearers in much the same way as they might view animals: motivated by instincts, concerned only about their own welfare, unintelligent, and a challenge to tame». En nuestro corpus de análisis sólo aparece una mujer ataviada con ropa con huellas animales, sin embargo su pose es muy forzada, dura y geométrica, de manera que invita más a asociarlo con lo estrambótico que con lo sensual. (Imagen 9) 
Representación de la minoría entre la minoría: relaciones inter-género e inter-étnicas en...

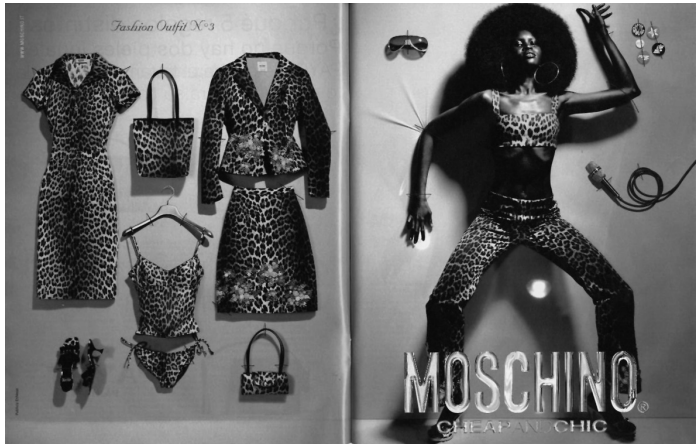

Imagen 9 .

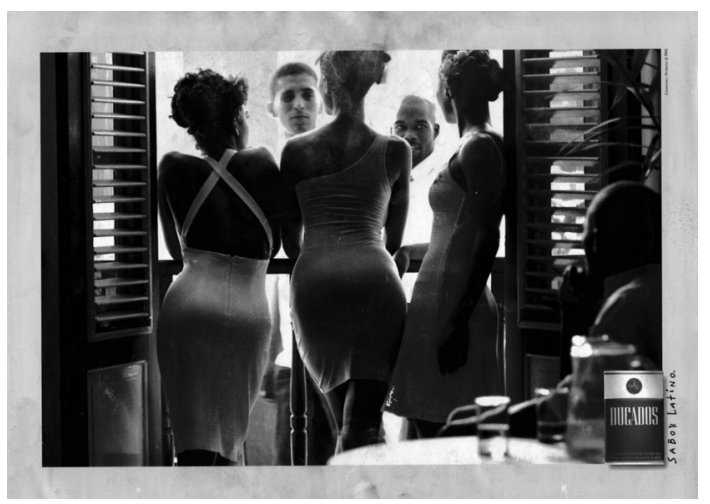

cen al mismo grupo étnico. Comparten culpa y raza. La reticencia a mezclar parejas se hace más evidente en las escenas grupales con variedad de sexo y raza, donde se tiende a permitir el contacto físico únicamente entre quienes comparten grupo étnico (imagen 8). En otras ocasiones sí aparecen mezclados en el mismo contexto hombres y mujeres de variados grupos étnicos, pero están compartiendo actividades de ocio, de manera que lo que se percibe es un vínculo de amistad, no de pareja. Tanto en la pareja en potencia, representada porque escenifica una acción de cortejo, como en la pareja de facto, representada por el contacto físico, se mantiene el statu quo intra-étnico (imágenes 4, 5, 6, 7 y 8).

Imagen 4.

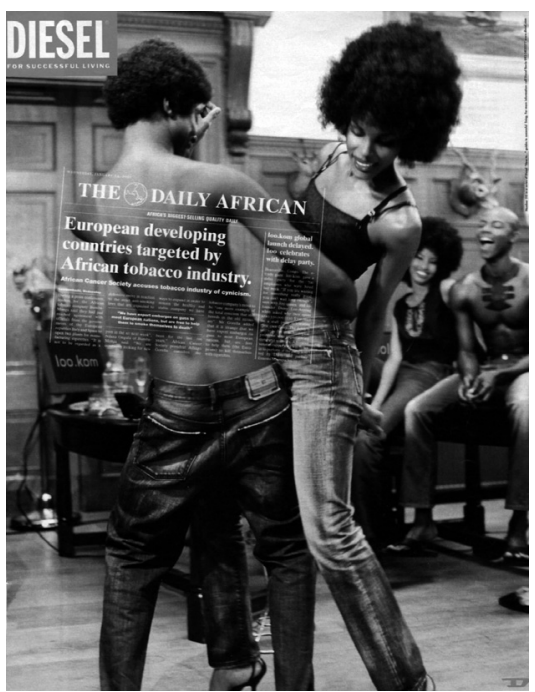

Imagen 5 .

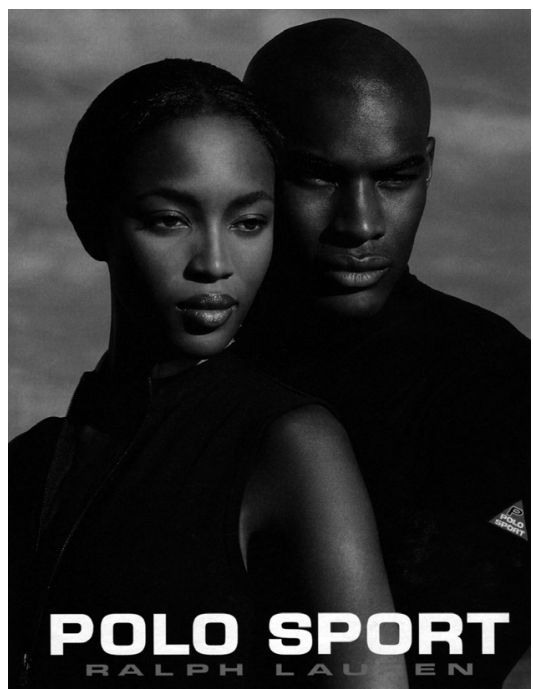

Imagen 6. 
Patricia Izquierdo Iranzo
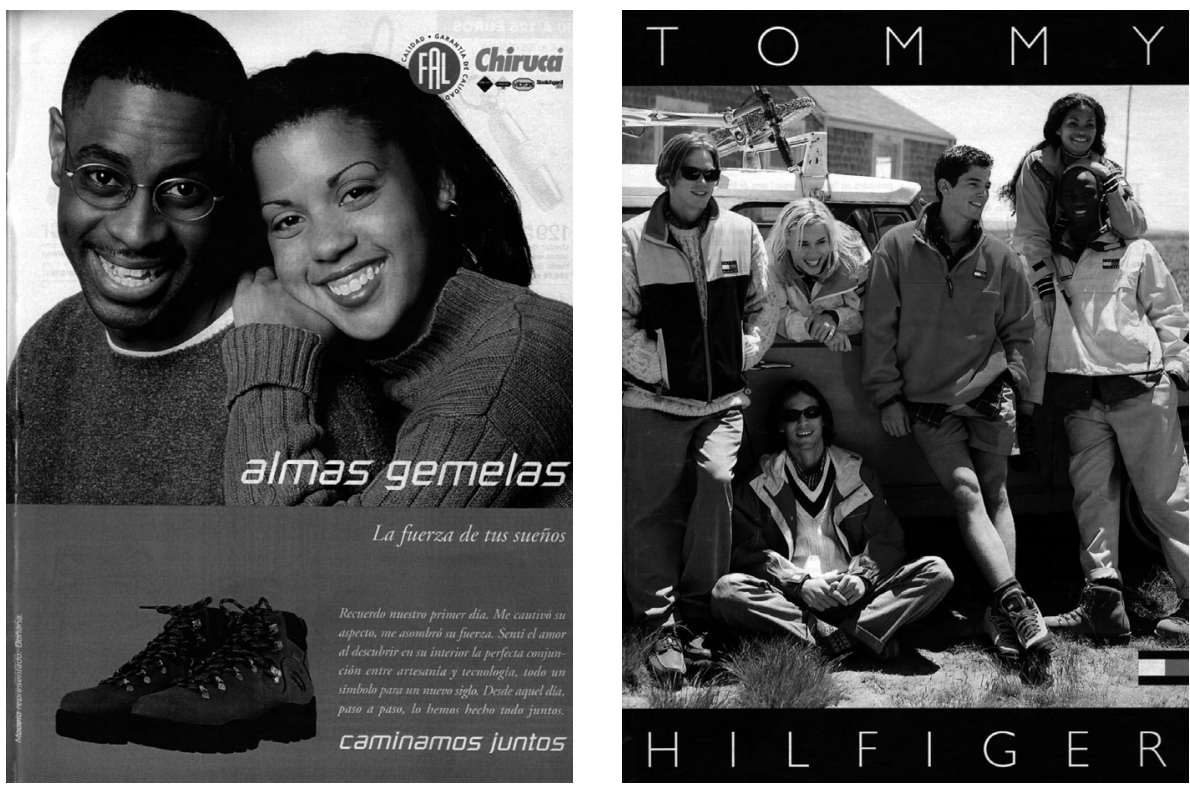

Imagen 7.

Imagen 8.

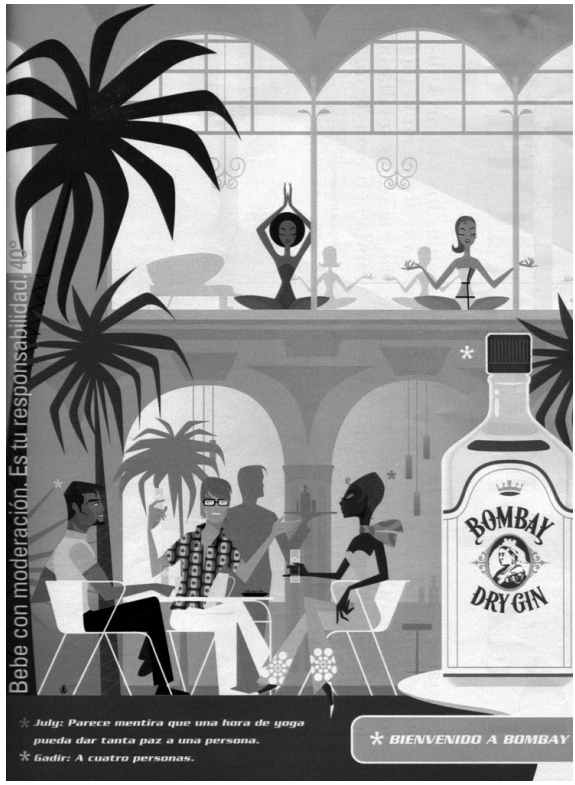

Imagen 10.

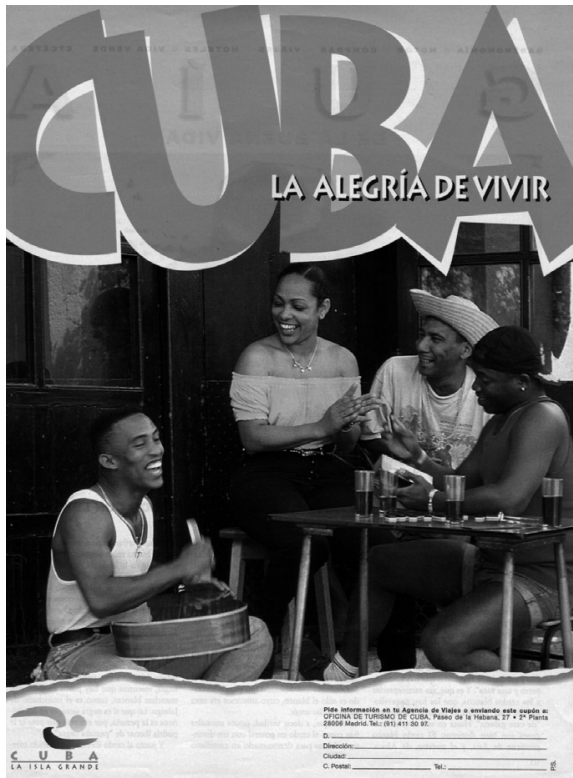

Imagen 11. 
Representación de la minoría entre la minoría: relaciones inter-género e inter-étnicas en...

Entre los anuncios aludidos en los que mujeres y hombres de diferentes grupos étnicos comparten escenas de ocio y diversión percibimos dos tipos de contextos, uno más moderno, con estéticas más vanguardistas y acento de internacionalidad (imagen 10) y otro con un marcado carácter de fiesta popular (imagen 11). La presencia de la mujer étnica en el primero sirve para aportar un toque más a la idea de cosmopolitismo, mientras que en el segundo se justifica porque ella pertenece al lugar.

Grados del uso sexual de la mujer étnica a través de sus relaciones de pareja en el discurso publicitario

\begin{tabular}{|l|l|l|c|}
\hline \multicolumn{1}{|c|}{ Categoría } & \multicolumn{1}{|c|}{$\begin{array}{c}\text { Grupo étnico por } \\
\text { género }\end{array}$} & \multicolumn{1}{|c|}{ «Culpabilidad» } & $\begin{array}{c}\text { Imágenes } \\
\text { (de menor a mayor } \\
\text { «estabilidad» de la } \\
\text { pareja) }\end{array}$ \\
\hline $\begin{array}{l}\text { Depredadora de } \\
\text { hombre blanco en } \\
\text { acción }\end{array}$ & $\begin{array}{l}\text { Ella = mulata o negra } \\
\text { Él= blanco }\end{array}$ & $\begin{array}{l}\text { Recae exclusivamente } \\
\text { en ella }\end{array}$ & 1 \\
\hline $\begin{array}{l}\text { Depredadora } \\
\text { buscando víctima }\end{array}$ & $\begin{array}{l}\text { Ella= mulata } \\
\text { Él= inexistente }\end{array}$ & $\begin{array}{l}\text { Recae exclusivamente } \\
\text { en ella }\end{array}$ & 2,3 \\
\hline $\begin{array}{l}\text { Provocación femenina } \\
\text { con respuesta } \\
\text { masculina }\end{array}$ & $\begin{array}{l}\text { Ella y él del mismo } \\
\text { grupo étnico }\end{array}$ & $\begin{array}{l}\text { «Compartida» con } \\
\text { mayor o menor } \\
\text { igualdad }\end{array}$ & 4,5 \\
\hline Pareja & $\begin{array}{l}\text { Ella y él del mismo } \\
\text { grupo étnico }\end{array}$ & $\begin{array}{l}\text { No hay culpabilidad, } \\
\text { no hay rito de cortejo }\end{array}$ & 6,7 \\
\hline
\end{tabular}

La utilización puramente estética y corporal de la mujer de rasgos no autóctonos llega a no tener ninguna connotación negativa desde la perspectiva étnica, aunque sí desde la de género. Es decir, que responde a usos sexistas pero en la misma medida que se hace con la mujer blanca ${ }^{37}$. Concretamente la mujer negra, publicitariamente hablando, ha alcanzado un altísimo estatus en la representación de la belleza, no se la utiliza únicamente desde la perspectiva más vulgar de los primeros ejemplos explicados, sino que se la llega a considerar válida para ser portadora de la mismísima elegancia (imagen 12). Simbolizar la belleza elegante históricamente había sido un privilegio reservado en la iconografía mundial a la mujer blanca, sin embargo hemos comprobado cómo, además de la mujer negra, también empieza a ser progresivamente interpretado por la mujer asiática, cuyo estereotipo quizá si ha estado siempre más asociado

37. Un dato que avala esta hipótesis es que son varias las investigaciones que han encontrado que el nivel de desnudo publicitario en la mujer ha ido aumentando progresivamente en los últimos años, pero tanto en la mujer blanca como en la negra: «It is clear that the exposure of breasts, cleavage, and other areas of the body has become commonplace for both Black and White female models», en Plous, S. and NePTUNe, D.: Op. cit., p. 635. También en Millard, Jennifer E. and GRANT, Peter R.: Op. cit., p. 660, se nos habla de exposición corporal frecuente y creciente pero de manera igualitaria tanto para mujeres negras como blancas. 


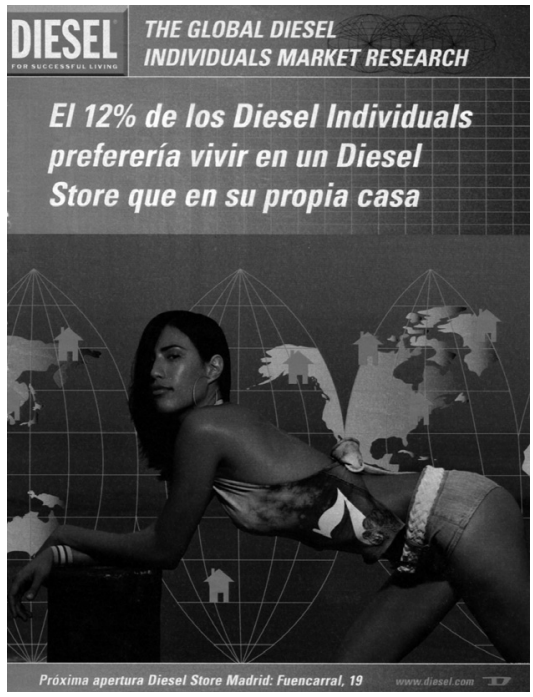

Imagen 3 .

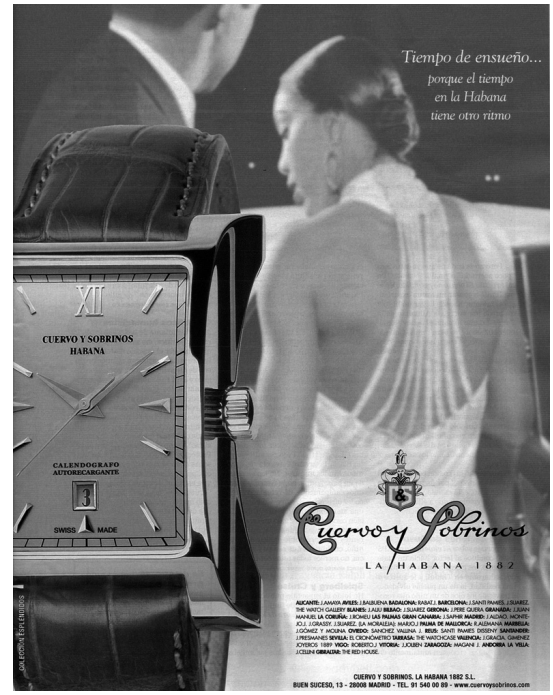

Imagen 12 .

a la delicadeza, pero también es cierto que, al menos en nuestro entorno, siempre ha sido más lejana y menos visible (imagen 13) ${ }^{38}$.

Una cuestión es abrir el coto de razas que pueden simbolizar la belleza más delicada y distinguida y otra es "perder» el dominio. Hay un uso muy concreto de la variedad étnica femenina y es cuando el anunciante pretende ampliar su línea de producto a diver-

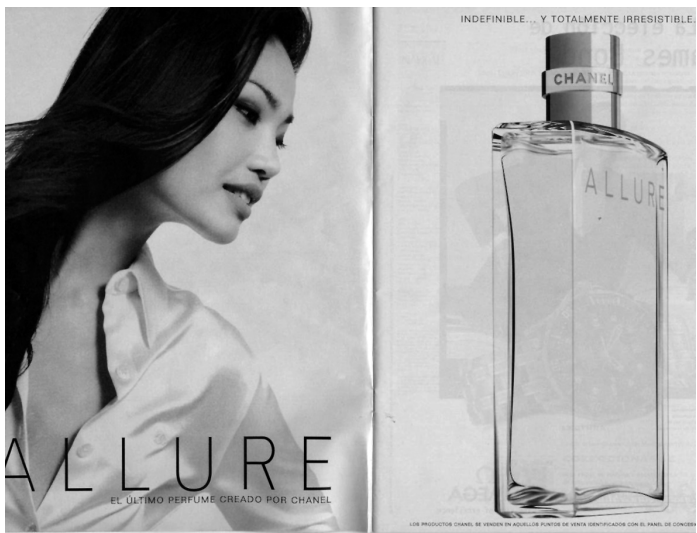

Imagen 13. sos targets $^{39}$; el ejemplo más habitual lo encontramos en las marcas de maquillaje que recurren a esta variedad representativa con la intención de dirigirse a sus diferentes targets o "clientas» con diversos tonos de piel. Lo que llama la atención es que sólo en una ocasión cuando han aparecido tres mujeres cada una representaba una etnia: latina, caucásica y negra, en el resto de casos siempre que aparecían tres mujeres dos

38. Todo ello pese a que los hombres siguen considerando como icono de belleza a la mujer caucásica, en Coltrane, Scott and Messineo, Melinda: Op. cit., p. 369.

39. Término técnico de la profesión publicitaria para referirse a los diversos grupos cuyas variables sociográficas los convierten en consumidores potenciales de ofertas concretas. 
Representación de la minoría entre la minoría: relaciones inter-género e inter-étnicas en...

eran caucásicas y una negra (imagen 14).

\subsection{Uso "pasaporte" $y$ comparativo}

También se recurre al uso de la mujer de rasgos no autóctonos para representar la lejanía. En ocasiones se pretende transmitir que el producto publicitado no tiene fronteras y esa distancia sim-

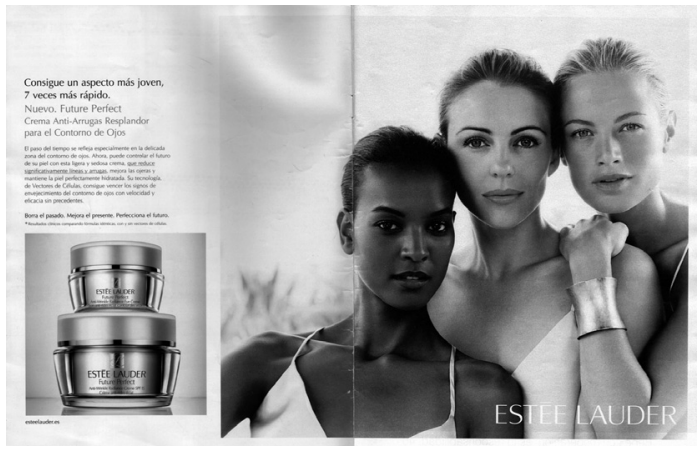

Imagen 14.

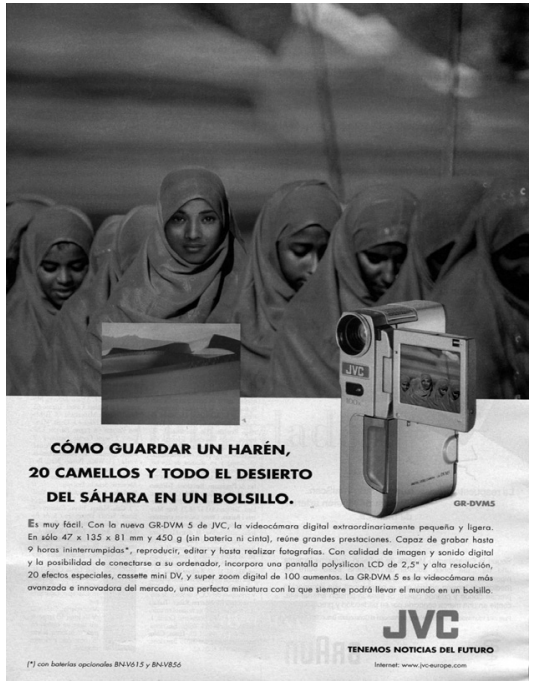

bólica viene aludida a través de mujeres de otros lugares; la presencia de la mujer étnica se convierte en una metáfora de la versatilidad y la ubicuidad del producto (imagen 15). Este uso metafórico de transporte a lugares lejanos es muy recurrente en las campañas de destinos turísticos (imagen 11), en las de productos con denominación de origen (imagen 16) y también en las de ONGs (imagen 17). En todas ellas la mujer étnica en su condición de decorado natural hace más

Imagen 15.

creíble lo remoto de la escena y ayuda al lector a transportarse mentalmente a ese lugar lejano. En esta línea simbólica es habitual también la utilización de las consideradas como características endógenas a cada etnia: destaca sobre todo la aparición de la mujer negra dominando actividades deportivas y las relacionadas con la música y el baile. En este grupo caben también usos metafóricos más simples: publicitariamente hablando, el pelo afro de la raza negra ha dado mucho juego tanto en hombres como en muje-

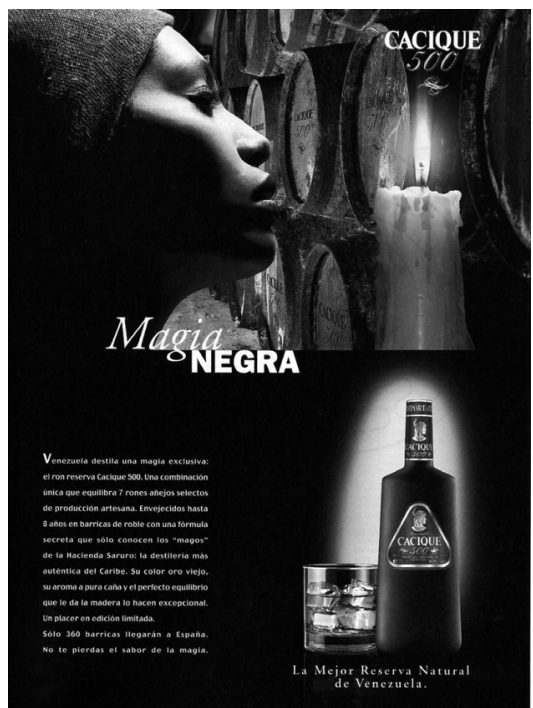

Imagen 16. 


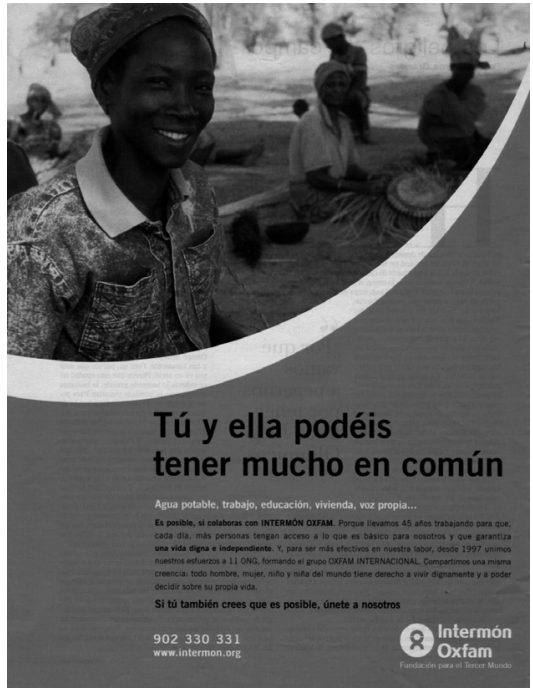

Imagen 17.

res; por ejemplo no hay mejor manera visual de probar la fuerza alisadora de un secador que mostrando un antes $y$ un después de su uso sobre el encrespado cabello afro de una mujer negra. Del resto de mujeres no-blancas y no-negras, no tenemos constancia en este sentido, el desconocimiento de ellas impide utilizar sus características positivas con fines publicitarios.

Afortunadamente no hay evidencia de usos abiertamente discriminatorios; por ejemplo, entre las 96 mujeres analizadas, sólo hemos encontrado una única mujer negra ejerciendo el papel de limpiadora, lo cual contrasta radicalmente con los resultados de aquellas primeras investigaciones de los años 50: «(..) magazine advertisements that contained photographs and drawings of Black people repeatedly represented them in service occupations, such as maids or waiters, and as always belonging to the lowest occupational category» ${ }^{40}$.

Sin embargo observando la tipología de productos en los que aparecen mujeres étnicas, sí se detecta cierta tendenciosidad. Más de la mitad de ellas $(52 \%)$ concentran su aparición únicamente en cuatro de los sectores en los que Infoadex ${ }^{41}$ divide la oferta de productos y servicios: Belleza e higiene $(17,71 \%)$, Textil $(13,54 \%)$, Bebidas alcohólicas $(12,50 \%)$ y Tabaco $(10,42 \%)$. Podemos observar que estos cuatro sectores por sus tipologías de productos inducen a escenarios más asociados con el ocio, la celebración, la diversión... nada que ver con ambientes de responsabilidad o intelectualidad. Si nos fijamos además éstos son sectores muy simbólicos, es decir, aquellos en los que la publicidad menos recurre a argumentaciones lógicas para defender su contenido.

\subsection{La mujer inmigrante en la publicidad española}

Las representaciones analizadas hasta el momento corresponden a mujeres cuyos rasgos físicos no coinciden con los de la mujer autóctona, es decir, que pese a los riesgos anteriormente comentados del uso de este indicador, en principio estaríamos hablando de extranjeras y, como también explicamos, publicitariamente hablando es la manera más cercana para observar la cuestión

40. Shuey, A.M.; King N. and Griffith, B.: Op. cit., citado por Millard, Jennifer E. and Grant, Peter R.: Op. cit., p. 661.

41. Infoadex, fuente de referencia en España sobre los datos de inversión publicitaria, en http:// www.infoadex.es/infoadex.asp 


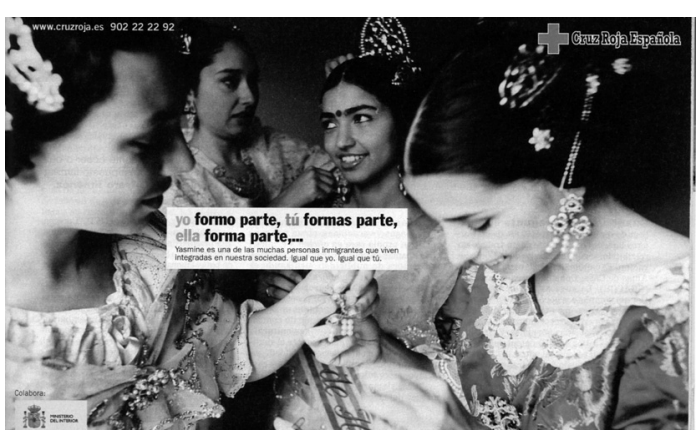

Imagen 18.

inmigratoria en la publicidad. Sin embargo del conjunto de mujeres analizadas hasta ahora, independientemente de su situación jurídica de nacionalidad o su estatus social, sólo una ejercía de inmigrante (imagen 18). Es una campaña correspondiente al año 2002, de una ONG abogando por la integración, aunque entendemos que la escena diseñada para tal fin no es la más adecuada ya que parece apostar más por el llamado integracionismo, que por la normalización de la diversidad.

Actualmente los anunciantes españoles utilizan la imagen de inmigrantes ejerciendo como tal cuando entre sus clientes quieren captar también a inmigrantes y optan por generar campañas específicas para ellos, especialmente en sectores en los que se están consolidando como clientes potentes: banca y telefonía (donde ya superan el gasto de los autóctonos). Otro bloque de publicidad que representa a inmigrantes es el de productos especialmente dirigidos a ellos (empresas de envío de dinero, peluquerías étnicas, restaurantes típicos...) y donde los autóctonos no son consumidores potenciales, por tanto las inserciones de estas campañas se limitan a su vez a medios dirigidos especialmente a inmigrantes. También hay presencia de mujeres inmigrantes en las campañas institucionales de las diferentes administraciones dando cuenta de su gestión en materia social. La inmensa mayoría de estas campañas emplea a mujeres latinoamericanas (imágenes 19 y 20) ${ }^{42}$; esta sobre-representación publicitaria contrasta con la escasa aparición de mujeres de otros grupos étnicos, pero a nuestro entender tiene una clara explicación: según las encuestas las latinoamericanas son las inmigrantes que más simpatía

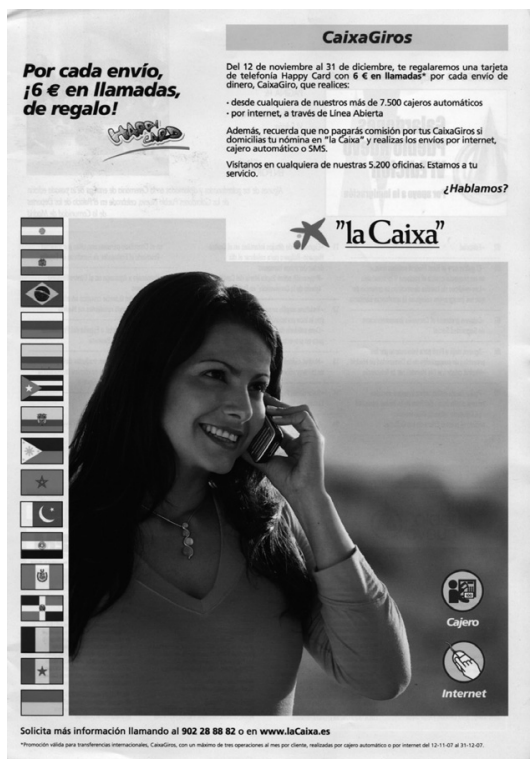

Imagen 19.

42. Dado que en el corpus seleccionado no hay unidades que ilustren los casos referidos, éstos dos ejemplos han sido extraídos de otras publicaciones. 


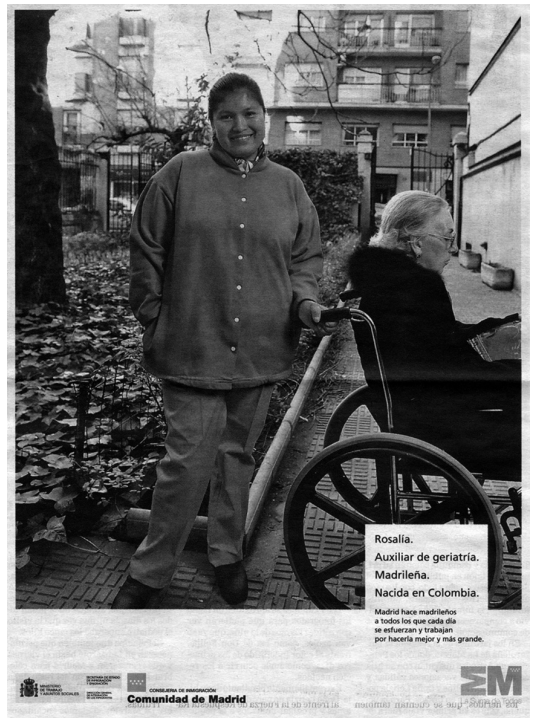

Imagen 20. y confianza generan entre la población autóctona ${ }^{43}$.

Más allá de no compartir esta línea de especialización publicitaria sobre la inmigración que está surgiendo con fuerza en los últimos años en España ${ }^{44}$, porque invita más hacia la segregación que hacia la normalización de la diversidad, vemos necesario comparar este uso de la mujer étnica con los anteriormente descritos.

En el primer gran grupo analizado (Jezebel), la mujer era muy bella y joven ("en edad sexual»), en el segundo, el de los usos "pasaporte» y metafóricos, no tenía necesariamente por qué ser hermosa aunque sí lo era en la mayoría de los casos, y en este tercer grupo en el que la mujer étnica ejerce de inmigrante tampoco se necesita expresamente que sea atractiva y joven aunque en ocasio-

nes pueda serlo. Esto nos permite establecer dos categorías bien diferenciadas respecto al uso publicitario de la mujer con rasgos no autóctonos: unas son modelos (mayoritariamente negras y entre las que también se empieza a incluir a las modelos orientales) cuya principal característica y valor es que son bellas, y la segunda categoría son mujeres de fuera, cuya principal característica y valor es que son lejanas.

43. ACtis, Walter, Pereda, Carlos y PradA, Miguel Ángel de: Experiencias de discriminación de minorías étnicas en España, Madrid, Colectivo IOÉ, 2003.

44. El fenómeno de la "especialización étnica» se está consolidando en nuestro país en los tres últimos años aproximadamente, desde las agencias de publicidad hasta grandes anunciantes que crean divisiones dentro de sus departamentos de marketing dedicadas a conseguir la forma más eficaz de llegar a estos targets potenciales. Aunque algunos quieran ver en esta postura un avance hacia la integración, dirigir nuestra atención a los inmigrantes valorándoles únicamente como nuevos clientes no parece el camino más adecuado para la lograr la verdadera convivencia. Esta opinión viene además respaldada por la experiencia acontecida en otros países: en Estados Unidos hace años que existen agencias divididas por el color de sus clientes y ninguna gran empresa pasa sin tener su departamento étnico, sin embargo el problema de representación de razas existe con su correspondiente extensión a la cotidianeidad de las sociedades: "After decades of research on racial and gender biases in magazine advertising, ample evidence exists that there is a problem. The challange now is to understand why this problem has been so resistant to change» (PlOUS, S. and NEPTUNE, D.: Op. cit., p. 641). 
Representación de la minoría entre la minoría: relaciones inter-género e inter-étnicas en...

\begin{tabular}{|l|l|l|l|l|}
\hline Significado del uso & $\begin{array}{c}\mathbf{N}^{\circ} \text { de } \\
\text { imagen }\end{array}$ & $\begin{array}{l}\text { Exigencia de } \\
\text { belleza }\end{array}$ & \multicolumn{1}{|c|}{ Grupo étnico } & $\begin{array}{l}\text { Categoría } \\
\text { publicitaria }\end{array}$ \\
\hline $\begin{array}{l}\text { «Jezebel»= uso de la } \\
\text { imagen física }\end{array}$ & $\begin{array}{l}1,2,3,4, \\
5,6,8,9, \\
10,12,13, \\
14\end{array}$ & Indispensable & $\begin{array}{l}\text { Mayoritariamente } \\
\text { mujer negra, empieza a } \\
\text { incorporarse la mujer asiática }\end{array}$ & Modelos \\
\hline $\begin{array}{l}\text { «Pasaporte»= uso } \\
\text { metafórico por } \\
\text { características del } \\
\text { grupo étnico }\end{array}$ & $\begin{array}{l}11,15,16, \\
17\end{array}$ & Habitual & Variedad & $\begin{array}{l}\text { Mujeres de } \\
\text { fuera } \\
\text { (siguen allí, } \\
\text { opueden } \\
\text { haber } \\
\text { venido aquî) }\end{array}$ \\
\hline $\begin{array}{l}\text { Inmigrante ejerciendo } \\
\text { de inmigrante }\end{array}$ & $18,19,20$ & No necesario & Latinas & \\
\hline
\end{tabular}

La primera categoría está formada por mujeres «imposibles», imposibles de conquistar para ellos e imposibles de imitar para ellas. La segunda categoría también marca barreras, culturales en este caso. En definitiva la manera en que la publicidad utiliza la diversidad femenina no contribuye al acercamiento con la población autóctona y por tanto no favorece ni el mutuo conocimiento ni el mutuo interés por la construcción de la convivencia.

\subsection{Integración: usos sustituibles vs. personas insustituibles}

Lo más destacable de la utilización publicitaria de la mujer no autóctona es que la doble condición se percibe como indispensable en muy pocas ocasiones. Es decir, que en la mayoría de ocasiones su presencia se justifica o por su raza o por su género, pero en pocas ocasiones por ambas a la vez. Por ejemplo en todos los casos del grupo "pasaporte» y metafóricos (lejanía, aptitudes para el deporte o la música...) las mujeres podrían haber sido sustituidas por hombres o niños de su misma raza y el significado del relato publicitario hubiera permanecido intacto. Por el contrario en el grupo de usos "Jezebel», las mujeres étnicas podrían haber sido sustituidas por mujeres no étnicas igualmente bellas y también se hubiera mantenido el mismo significado del anuncio. Únicamente parece ser más real la depredación al indiferente hombre blanco por parte de una mujer más salvaje y por tanto la presencia de la doble condición mujer-étnica es más necesaria. Definitivamente sólo parece insustituible en aquellas campañas que utilizan a la mujer no-blanca junto a la blanca para apelar a diferentes targets (lo cual sería comparable a explicitar que una prenda existe en varias tallas por lo que sirve a diversas mujeres). Es decir, que el único uso insustituible es aquel en el que se pretende crear una identificación entre la modelo y la clienta que comparten el mismo tono de piel y por tanto número de maquillaje. Sin embargo cuando la presencia de la mujer étnica se debe a su aporte de significado al conjunto del relato publicitario vemos que puede ser fácilmente sustituida, bien por sus compañeras de género, bien por sus compañeros de etnia.

El fácil reemplazo de la mujer étnica a la hora de aportar significado a una escena publicitaria nos habla de lo que ocurre en la escena de la vida, y si bien es cierto que este papel secundario de la mujer no-blanca no es una invención publicitaria, su incontestada y persistente reproducción en las campañas 
contribuye a perpetuar ese estatus social de inferioridad e incluso a validarlo. Cuestión ésta que obviamente no contribuye a la actitud que deben tener otros grupos respecto al aludido, pero menos aún ayuda al propio grupo afectado, especialmente en cuestiones de bienestar psicológico: "Research has shown that black women who endorse these stereotypic roles have lower self-esteem than those who do not which illustrates the negative psychological implications of these representations ${ }^{\star 4}$.

La integración es una cuestión compleja que depende tanto de factores externos como internos, la propia actitud se consolida como clave de este proceso, pero a su vez la autopercepción se construye a través de la percepción que uno tiene de cómo es percibido por los demás. La investigación científica ha constatado que las mujeres negras norteamericanas en su mayoría se sienten orgullosas de esta doble condición y reconocen "positive characteristics developed as a result of having overcome obstacles» ${ }^{46}$, sin embargo la mayoría está en total desacuerdo con los estereotipos existentes sobre su grupo. Ésta es una cuestión común en muchos escenarios, los inmigrantes en España no se sienten identificados con su imagen pública y es lógico puesto que esa imagen la crean los autóctonos. Parece entonces que es norma universal que los grupos minoritarios, entre otros vetos, tengan vetado el acceso a la creación de su propia representación ${ }^{47}$. En la introducción ya apuntamos la necesidad de continuar esta investigación indagando acerca de cómo la representación estereotipada de la mujer étnica en la publicidad influye en su integración social; hasta que podamos obtener datos empíricos ad hoc, los resultados obtenidos en estudios sobre cuestiones cercanas nos hacen ponernos en alerta: «(...) consistent depiction of gender or ethnic groups in stereotyped role portrayals, e.g., expert, victim, athlete or criminal, may have psychological consequences in the development of individuals' expectations, opportunities, and self-esteem ${ }^{\star 48}$.

\section{CONCLUSIONES}

Si la publicidad realmente incide en la interpretación e interacciones de nuestras vidas diarias ${ }^{49}$, hay que decir que esa influencia en las cuestiones aquí indagadas no resulta muy esperanzadora (aunque seguramente ese papel negativo no sea ejercido de manera consciente). De la investigación hemos deducido

45. Thomas, A. J.; Witherspoon, K. M. and Speight, S. L.: «Toward the development of the stereotypic roles for black women scale», Journal of Black Psychology, 30 (2004), pp. 426-442. Citado por SeTtLes, Isis H.: Op. cit., p. 590.

46. Ibíd., p. 595.

47. Sendín GutiérReZ, José Carlos e IzQuierdo IRANZO, Patricia: Guía práctica para los profesionales de los medios de comunicación: tratamiento de la inmigración, Madrid, Ministerio de Trabajo y Asuntos Sociales, 2008, pp. 7 y ss.

48. Beasley Delouth, Tara-Nicholle; Pirson, Brigitte; Hitchcock, Daryl and RienZI, Beth: Op. cit., p. 494.

49. «Even when we try to ignore television commercials, they make available a set of cognitive stereotypes that are called into play during routine interaction» (COLTRANE, S. and MESSINEO, M.: Op. cit., p. 385). 
que la mujer étnica puede ser fácilmente sustituida porque en realidad no se evidencia un aporte explícito de significado de su doble condición, bien se la usa como mujer bella y entonces puede ser sustituida por una mujer blanca bella, bien se la usa como referente de lejanía, y entonces se la puede sustituir por un hombre étnico que igualmente puede aportar la connotación de exotismo o nuevo cliente.

Es cierto que en la publicidad que actualmente se publica en España no hay una representación abiertamente discriminatoria de la mujer étnica, como sí ha ocurrido en otros países en sus comienzos, parece que los movimientos por las libertades y derechos civiles establecieron unos mínimos de "corrección política» que al menos en ámbitos de representación pública se mantienen. Lo que en otros lugares se ha tenido que conquistar aquí ya ha empezado como habitual. Sin embargo sí hemos encontrado indicios preocupantes: alta infra-representación y abundante estereotipación. Coincide además que estas circunstancias parecen ser habituales también en los contextos publicitarios de otros lugares, el hecho de que se repitan los mismos estereotipos en diversos territorios habla tanto de la internacionalización de la actividad publicitaria como de pautas comunes de significar determinadas parcelas de la vida en el ámbito mundial. Estas pautas afectan tanto al uso y codificación de lo étnico como al de lo femenino. En los relatos publicitarios la mujer, independientemente de su color, ha ido progresivamente conquistando escenarios públicos, pero esa liberalización paralelamente ha ido implicando un ascenso de su uso como objeto sexual, es como si hubiera cambiado un confinamiento por otro, de estar apresada en el hogar ha pasado a estarlo en su cuerpo. De esta manera los usos publicitarios de los roles de género y raciales no contribuyen internacionalmente a frenar el sexismo ni el racismo, por tanto la relación entre representación e integración es negativa.

Entendemos que éste es un fenómeno global que supera la representación local de cada contexto inmigratorio. Es decir que la mujer de rasgos no autóctonos no sufre severa estereotipación, como apuntaba la hipótesis de partida, por ser inmigrante sino por pertenecer doblemente a un grupo diverso al hegemónico que es blanco y masculino. De hecho, como hemos explicado, los valores esenciales de la categoría modelos no coinciden demasiado con los de la categoría mujeres de fuera, dentro de la cual a veces también se representa a alguna mujer inmigrante. Las modelos, mujeres bellas mayoritariamente negras, son utilizadas por la publicidad española con total independencia del fenómeno migratorio, no se relacionan ni en intensidad (proporción poblacional), ni en antigüedad, ni en variedad étnica... con la realidad multiétnica de las calles. Por otro lado, hay que constatar que cuando la publicidad utiliza a una mujer ejerciendo de inmigrante este uso no es discriminatorio sino utilitarista, bien se la necesita como clienta, bien se la necesita para ilustrar algún logro de la administración respecto a la gestión de la cuestión migratoria. 


\begin{tabular}{|l|l|}
\hline $\begin{array}{c}\text { Motivos de discriminación de la mujer de } \\
\text { rasgos no autóctonos en la sociedad }\end{array}$ & $\begin{array}{l}\text { Motivos de estereotipación de la mujer de } \\
\text { rasgos no autóctonos en la publicidad }\end{array}$ \\
\hline Por ser mujer & Por ser mujer \\
\hline Por pertenecer a un grupo étnico minoritario & $\begin{array}{l}\text { Por pertenecer a un grupo étnico } \\
\text { históricamente discriminado }\end{array}$ \\
\hline Por su estatus de inmigrante & \\
\hline
\end{tabular}

Por tanto el discurso publicitario no reproduce la consideración negativa que gran parte de la población autóctona tiene sobre los inmigrantes, como se apuntaba en la introducción, pero tampoco contribuye a la mutua integración, porque no refuerza positivamente la imagen de la mujer no autóctona, ni como mujer ni como extranjera, ya que el relato publicitario profundiza las distancias aspiracionales (modelos $=$ "mujeres imposibles») y las barraras culturales (mujeres de fuera $=$ culturalmente diferentes). En definitiva todo esto demuestra que la cuestión de la creación de identidades hoy en día supera el ámbito local y puede estar altamente influenciada por códigos de alta exportabilidad y con fuerte arraigo en plataformas de lanzamiento mundiales como es la publicidad.

\section{BIBLIOGRAFÍA (Únicamente referencias no citadas a pie de página)}

BelL, Joyce M. and HARTMAnN, Douglas: «Diversity in Everyday Discourse: The Cultural Ambiguities and Consequences of Happy Talk», American Sociological Review, 72:6 (2007), pp. 895-914.

CRAEMER, Thomas: "An Evolutionary Model of Racial Attitude Formation: Socially Shared and Idiosyncratic Racial Attitudes", The Annals of the American academy of political and social science, 614 (2007), pp. 74-101.

IZQUIERDO IRANZO, Patricia: «Publicidad y multiculturalidad: ¿Integración comercial o exclusión de identidades culturales?» en Actas del III Congreso Panamericano de Comunicación, Buenos Aires, Servicio Publicaciones de la UBA, Julio 2005.

— «Estereotipos publicitarios y violencia racial», Trípodos, n extra (2003), pp. 705-719.

- Comunicación, migración y metodología. Un experimento para observar la legitimación de los valores eurocentristas en los contenidos mediáticos, Madrid, Servicio de Publicaciones de la URJC, 2002.

MClaughlin, Tara L. and Goulet, Nicole: "Gender Advertisements in Magazines Aimed at African Americans: A Comparison to Their Occurrence in Magazines Aimed to Caucasians», Sex Roles, 40:1/2 (1999), pp. 61-71.

RODRÍGUEZ JimÉNEZ, José Luis e IZOUIERDO IRANZO, Patricia: «Extrema derecha y discurso xenófobo", en VV.AA: Informe anual 2007 sobre el racismo en el Estado español, Barcelona, Icaria, 2007, pp. 194-198.

WeMYss, Georgie: “'Outside Extremist', 'White East Enders’, 'Passive Bengalis': Tracking Constructions, Mobilizations and Contestations of Racial Categories in Media Discourses», Sage Race Relations Abstracts, 31:4 (2006), pp. 21-47.

Fecha de recepción: $\quad$ 08-04-2008

Fecha de aceptación: 19-05-2008 